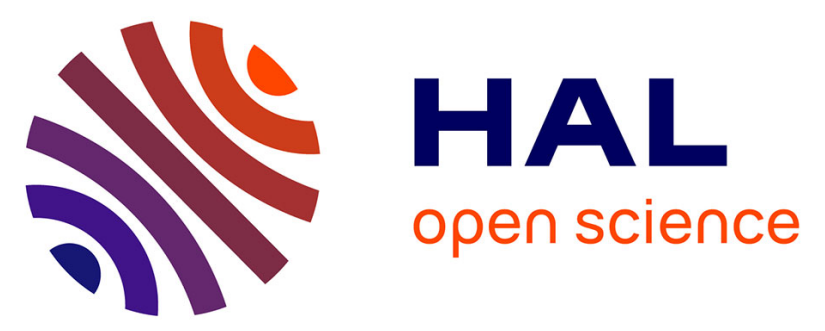

\title{
High-resolution grain size distribution of sediment core with hyperspectral imaging
}

Kevin Jacq, Charline Giguet-Covex, Pierre Sabatier, Yves Perrette, Bernard Fanget, Didier Coquin, Maxime Debret, Fabien Arnaud

\section{- To cite this version:}

Kevin Jacq, Charline Giguet-Covex, Pierre Sabatier, Yves Perrette, Bernard Fanget, et al.. Highresolution grain size distribution of sediment core with hyperspectral imaging. Sedimentary Geology, 2019, 393-394, pp.105536. 10.1016/j.sedgeo.2019.105536 . hal-02373649

\section{HAL Id: hal-02373649 \\ https://hal-sde.archives-ouvertes.fr/hal-02373649}

Submitted on 21 Dec 2021

HAL is a multi-disciplinary open access archive for the deposit and dissemination of scientific research documents, whether they are published or not. The documents may come from teaching and research institutions in France or abroad, or from public or private research centers.
L'archive ouverte pluridisciplinaire HAL, est destinée au dépôt et à la diffusion de documents scientifiques de niveau recherche, publiés ou non, émanant des établissements d'enseignement et de recherche français ou étrangers, des laboratoires publics ou privés.

\section{(ㅇ)(1) $\$$}

Distributed under a Creative Commons Attribution - NonCommerciall 4.0 International 


\section{High-resolution grain size distribution of sediment core with}

\section{2 hyperspectral imaging}

3

4 Kévin Jacq ${ }^{1,2}$, Charline Giguet-Covex ${ }^{1}$, Pierre Sabatier ${ }^{1}$, Yves Perrette ${ }^{1}$, Bernard Fanget ${ }^{1}$, Didier

5 Coquin $^{2}$, Maxime Debret ${ }^{3}$, Fabien Arnaud ${ }^{1}$

6

71 Univ. Grenoble Alpes, Univ. Savoie Mont Blanc, CNRS, EDYTEM, 73000 Chambéry, France

82 Laboratoire d'Informatique, Systèmes, Traitement de l'Information et de la Connaissance (LISTIC),

9 Université Savoie Mont-Blanc, 74944 Annecy Le Vieux Cedex, France

3 Laboratoire de Morphodynamique Continentale et Côtière, Université de Rouen, UMR CNRS 6143,

Corresponding Author:

Université Savoie Mont Blanc, Campus scientifique, 


\section{Abstract}

The study of sediment cores allows for the reconstruction of past climate and environment through physical-chemical analysis. Nevertheless, this interpretation suffers from many drawbacks that can be overcome with the newest technologies. Hyperspectral imaging is one of these and allows a fast, high resolution, and non-destructive analysis of sediment cores. In this study, we use visible and near-infrared hyperspectral imaging to predict particle size fractions and distribution (PSD) at a resolution of $200 \mu \mathrm{m}$ on a previously well-studied sediment core taken from Lake Bourget (Western Alps, France). These predictions agree with previous studies on this core. Then, the PSD was used to estimate sedimentary deposit sources using the PSD unmixing algorithm AnalySize. It permitted estimation of the contribution of five sources (micrite, small and large bio-induced calcite crystals, diatom frustules, detrital particles), which had previously been characterized. The spatial dimension allowed for laminae to be discretized and counted, in agreement with the age-depth model previously established. We then evaluated the particle size and spectral signatures of each of these annual laminae, hence characterizing their physico-chemical composition. These high-resolution data also allowed for estimation of the accumulation rate (cm/year) of each of the main sources in the laminated unit and inferring the trophic status and the presence of instantaneous events of the lake.

Keywords: Grain size distribution, Hyperspectral Imaging, Chemometrics, Visible and Near-Infrared Spectroscopy, End-Members 


\section{Introduction}

Particle size analysis is widely used in sediment studies. Several methods exist, such as gravimetric sedimentation, sieving or laser diffraction. The last one is the most used for fine lacustrine sediment. Such laboratory analyses of sediment textures are time and material consuming, labor-intensive, destructive and have low spatial resolution (0.5-1 cm sampling-steps are typically run) and thus temporal resolution. Spectroscopic methods show great possibilities to estimate particle size fractions (clay, silt, sand) without any sampling (Viscarra Rossel et al., 2016; de Santana et al., 2018; Nanni et al., 2018). The classically used coarser fractions, i.e., silt and sand, seem the most complicated to predict in several studies (de Santana et al., 2018; Nanni et al., 2018). The physical properties of the sediment can be estimated with the spectra baseline that is affected by the grain size in the visible and near-infrared ranges (Wetzel, 1983). It was also done in remote sensing with multispectral imaging (Casa et al., 2013; Demattê et al., 2015; Nouri et al., 2017). Multi- and hyperspectral imaging are methods in the interface of spectroscopy and imaging with the acquisition of an image in which each pixel is characterized by a reflectance spectrum. Recently developed hyperspectral core loggers open new possibilities for the high-resolution prediction of organic matter (Van Exem et al., 2018; Jacq et al., 2019b) and pigments (Butz et al., 2017) and could thus be used also for the estimation of particle size.

The particle size distribution (PSD) is even more informative than the particle fractions. Some studies show the potential of visible and near spectroscopy to estimate the PSD (Hermansen et al., 2017). To go further, the PSD allows for differentiation and quantification of the different compounds of the sediment (deposition sources, processes), each of which is characterized by its PSD signature. Several algorithms have been proposed to estimate the relative contribution of these pure signatures in a sediment mixture (Heslop et al., 2007; Dietze et al., 2012; Paterson and Heslop, 2015; Yu et al., 2016; 
Zhang et al., 2017). Van Hateren et al. (2017) argued that only a statistical comparative study of these estimated end-members and or a geological background could validate these signatures. The particle size end-member analysis of annually deposited sediments permits discrimination of allochthonous and autochthonous compounds to study varve formation and seasonal deposit variations over time (Żarczyński et al., 2019). The estimated end-members also allow for characterization of their relative abundance in each sample and therefore through time. It is also interesting to study instantaneous events, such as floods, to estimate their intensity for example.

This study aims to use hyperspectral imaging to estimate particle size fractions and distribution, then to estimate and characterize end-members. Partial least squares regression (PLSR) is one of the most used multivariate methods for the development of a quantitative predictive model with spectroscopic and physical-chemical data. PLSR is used to estimate particle size fractions and distribution in the same way as for organic matter (Jacq et al., 2019b). Two hyperspectral imaging sensors were used to cover the spectroscopic ranges from visible to near-infrared light (Vis-NIR: 400$2500 \mathrm{~nm}$ ). A laser grain-sizer was used to estimate the particle size distribution and then after statistic treatment, the main fractions and other variables (D50, D90, skewness, kurtosis). The AnalySize Matlab function was used to unmix the PSD end-members and to estimate their abundance along the core. The proposed methodology is applied to a Lake Bourget sediment core and is compared with previous studies (Giguet-Covex et al., 2010; Jenny et al., 2013, 2014). Then, the end-members were used to characterize the annual laminations (varves), to count them, to estimate their accumulation rate per year and their Vis-NIR signatures.

\section{Site description}

Lake Bourget is a hard-water lake, $18 \mathrm{~km}$ long and $2.8 \mathrm{~km}$ wide, located at an altitude of $231.5 \mathrm{~m}$ at the northwestern edge of the French Alps (Fig. 1). The rivers Leysse and Sierroz flow into Lake 
Bourget, which then flows into the Rhone River by the Saviere Channel under normal hydrological conditions. However, during major floods, water from the Rhone River flows into Lake Bourget with the reversal of the water-current of this channel. The sediment is mainly composed of river-borne silicate, between $10-40 \%$, and carbonate, between $60-90 \%$. The ratio between these two compounds varies depending on past climate conditions (Arnaud et al., 2005, 2012; Debret et al., 2010; GiguetCovex et al., 2010; Jenny, 2013; Jenny et al., 2014).

The location of core LDB09-P101 (length $=54 \mathrm{~cm}$, width $=9 \mathrm{~cm}$ ) was selected in the northern basin of

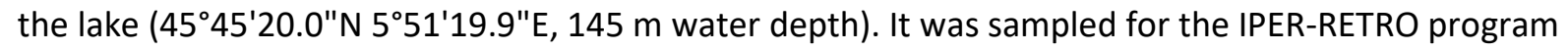
(ANR-08-VUL 005; Perga et al., 2015)). This site was selected because it contains both laminated sediments as well as interbedded deposits triggered by the Rhone River (Jenny, 2013).

\section{Materials and methods}

\subsection{Sample preparation and measurement}

The core was divided into two halves, one that was used for PSD and several destructive analyses, the other used for non-destructive analysis such as the hyperspectral imaging. This LDB09-P101 core is correlated to dated reference cores sampled in this lake, thanks to radionuclides $\left({ }^{210} \mathrm{~Pb},{ }^{137} \mathrm{Cs}\right.$, ${ }^{241} \mathrm{Am}$ ), historically known instantaneous events and varve counting (Jenny, 2013).

\subsubsection{Particle size distribution}

Particle size distribution (PSD) analyses were carried out on bulk sediments ( $5 \mathrm{~mm}$ thick, $\mathrm{n}=18$ ) using a Malvern Mastersizer 800S. This device uses the laser diffraction principle to estimate the particle diameter and estimate a distribution of them for 64 known classes between $0.06 \mu \mathrm{m}$ and $800 \mu \mathrm{m}$. Then statistics allowed to calculate the mean particle size, several percentiles (e.g., median, D90, D99), mode, sorting, and particle size fraction (clay, silt, sand). 
107 A hyperspectral image (HSI) is an image with high spatial resolution, in which each pixel contains a spectrum with a continuous spectral resolution.

The core was analyzed with two hyperspectral sensors (Specim Ltd., Finland) presented in Table 1 with the lens OLES22,5 at the M2C lab, University of Normandie-Rouen.

The sediment core must be as flat as possible for the analysis, so cleaning of the core was made, that also revealed the finest sediment structures. Spectral calibration of the camera was made with a spectralon reference to have reliable intensity. The spatial calibration was achieved by imaging a known object to obtain its true shape and thus obtain squared pixels. The calibration was checked at the end of the acquisition and no deviation was observed. More details about the acquisition protocol can be found in Butz et al. (2015).

A composite sensor was created by down-sampling the VNIR sensor at $200 \mu \mathrm{m}$ and a spatial registration to fit spatially the two hyperspectral images. The registration was made with the moisture content that can be recovered in the two sensors at $970 \mathrm{~nm}$ for the VNIR and at $1200 \mathrm{~nm}$ for the SWIR (Ce Liu et al., 2011; Jacq et al., 2019a). The SWIR image was registered on the VNIR one, because it has a lower resolution. Thus, a deformation model was estimated with these wavelengths and used on all the SWIR spectral planes. Then the two registered hyperspectral images were put together to create a composite sensor that covers the wavelengths between $400 \mathrm{~nm}$ and $2574 \mathrm{~nm}$. It was not possible to up-sample the SWIR sensor at $50 \mu \mathrm{m}$ because the spatial details cannot be estimated (Jacq et al., 2019a).

\subsection{Data Analysis}


ENVI 4.8 was used to perform the data acquisition. Then, MATLAB (R2018a, MathWorks) was used

128 for advanced processing and analyzing these data. PLSR was used to establish a relationship between

129 the HSI and the PSD of the core to create predictive models and then to estimate the PSD in each pixel. Then AnalySize Matlab function was used to unmix the predicted PSD to find pure sources (Paterson and Heslop, 2015).

\subsubsection{Predictive model estimation}

A multivariate method was used to create quantitative predictive models with the particle size and the VNIR-SWIR spectra of the core. Several noisy bands due to the detector were removed on two sides of the spectra of each sensor; consequently 202 of 242 wavelengths were used. An autoscale spectral pre-processing was realized to reduce the matrix effect. Calibration spectra are median spectra of the particle size sampling areas.

PLSR was used to model the relation between the spectra and the reference particle size values. This method is based on the extraction of orthogonal predictor variables (also called latent variables, LV) corresponding to the maximum variability in the spectral bands used as predictors linked to one or several predicted variable(s) (Wold et al., 1984). Two main algorithms exist, called PLS1 and PLS2, the difference is the number of dependent variables to predict. PLS1 is used when a single variable is predicted. When there are several variables to predict, several PLS1 can be realized, or a single PLS2 if variables to predict are dependent. PLS1 was used to predict particle size fractions, whereas PLS2 to predict the PSD because the fine particle fractions are highly correlated and co-dependent. The spectra register some biological-physical-chemical properties of the sample. For a specific proxy, all these spectral information were not mandatories, so we decided to use a variable selection algorithm (random frog, genetic algorithm) with the PLSR. This allowed to find the most relevant wavelengths, decrease redundancy and to interpret the model chemically. More details about this 
methodology can be found in Jacq et al. (2019b). Model accuracy was estimated with calibration and validation correlation coefficients and its uncertainty (Unc (\%)). Another correlation is calculated between the median predictions of the sampling areas and the reference PSD to validate that the surface acquisition by hyperspectral methods contains the volume information of the particle size analyses $\left(r_{v / s}\right)$.

\subsubsection{Sedimentary deposition sources discrimination}

Each PSD is a mixture of pure sub-PSD, that can be related to some specific sediment source. The Matlab function AnalySize (Paterson and Heslop, 2015) was used to unmixed each PSD and find these end-members. The assumption behind this function is a linear model equation (Eq. 1):

$$
X=A \times S^{T}+E
$$

with $X$ the reference PSD profile, $A$ the estimated abundance, $S^{\top}$ the estimated PSD of the pure components and $\mathrm{E}$ the residual matrix.

The intensity of the PSD and its abundance should not be negative. Thus, non-negative spectra and concentrations constraints were used. Another constraint was added to have the sum of abundance and the intensity of $S^{\top}$ at 1.

AnalySize allows estimating end-members in two ways. One is called non-parametric end-member analysis (EMA) that estimates end-members empirically from the whole dataset. The other uses a parametric distribution (Weibull, skewed generalized Gaussian distribution) to fit the PSD. A parametric distribution was chosen to unmix the predicted PSD to overcome uncertainties of the model prediction that disturb the sum of Gaussian theoretical distributions.

\section{Results}

\subsection{Lithology and particle size variations}

8 
171 The Lake Bourget sediment core presents three main units (Fig. 2b) that are mainly composed of clay

172 and silt fractions (Giguet-Covex et al., 2010).

173 Unit I, between 0 and $18 \mathrm{~cm}$ depth, presents millimeter-thick biochemical varves and corresponds to 174 perennial anoxic conditions at the lake-sediment interface, with a particle size mode near $22 \mu \mathrm{m}$ 175 (Giguet-Covex et al., 2010; Jenny, 2013). This facies is related to the development of human-triggered 176 lake eutrophication. It is characterized by a triplet of laminae made of different components (Giguet177 Covex et al., 2010) (Supplementary materials 1, 2). The lowermost lamina (dark-brown after 178 oxidation) is deposited in spring and is mainly composed of diatom frustules and large bio-induced 179 calcite crystals. The intermediate lamina (whitish to ochre after oxidation) is deposited in summer. It 180 is composed of large and mostly small calcite crystals, micrite, few diatoms frustules and organic 181 matter. The uppermost grey lamina corresponds to the winter deposit, which mainly contains organic matter and detrital particles. Some years a bloom of diatoms can occur in the fall. The presence of the large bio-induced calcite crystals and a high amount of diatoms is characteristic of the eutrophication period.

Unit II, between $18 \mathrm{~cm}$ and $26 \mathrm{~cm}$ depth, presents disturbed varves with a decreasing particle size mode from $22 \mu \mathrm{m}$ to $6 \mu \mathrm{m}$. Unit III, between $26 \mathrm{~cm}$ and $54 \mathrm{~cm}$, is characterized by fuzzy laminated structures and a particle size mode near $6 \mu \mathrm{m}$. In the two first units, there are also instantaneous event deposits mostly triggered by floods (Jenny et al., 2014). One major instantaneous event occurs between $13.5 \mathrm{~cm}$ and $14.5 \mathrm{~cm}$ (Fig. 2b).

Eighteen measurements of PSD were performed on the core with a range of the clay fraction between $14-68 \%$ with a mean of $40 \%$, and a range for the silt fraction between $30-71 \%$ and a mean of 53\%. Particle size fraction according to depth can be seen in Fig. $2 \mathrm{c}$ and the equivalent PSD in Fig. $3 b$. 
PLSR was used to generate quantitative models of the four main particle size fractions (clay, silt, very fine sand and fine sand) and also one to predict the 50 (out of 64) PSD classes from $0.15 \mu \mathrm{m}$ to 259 $\mu \mathrm{m}$ of the core. The other classes do not have enough variabilities or spectral information to be modeled. Consequently, five models were created. The performance of each is presented in Table 2. All the models are validated with correlation coefficients ( $r_{c a l}$ and $\left.r_{v a l}\right)$ and $r_{v / s}$ above 0.9 except for five classes between $6 \mu \mathrm{m}$ and $10 \mu \mathrm{m}$ of the PSD model with correlations greater than 0.5 (Supplementary material 3) due to very low variability in these classes. A similar number of selected wavelengths and LV was found between these models. Except for the silt fraction (4.0-62.5 $\mu \mathrm{m})$ with a higher number of LV that induces a more complex spectral modeling, this agrees with the five classes between 6-10 $\mu \mathrm{m}$ that present lower modeling performances.

The selected wavelengths of these models allow us to identify the structural information that are correlated with the particle size effect (Viscarra Rossel and Behrens, 2010; Jacq et al., 2019b). The selected wavelengths for the grain size fractions and PSD predictions are consistent. This allows for identifying precisely the spectral areas of each particle size fraction. Nine spectral areas can be seen (Fig. 4):

- (1) Carotenoids and/or iron oxides compounds can be associated with wavelengths around $470 \mathrm{~nm}$;

- $(2,3)$ Two other areas can be linked to the presence of iron oxides presence (around $550 \mathrm{~nm}$ and $625 \mathrm{~nm}$ );

- (4) Chlorophyll pigments absorb around $700 \mathrm{~nm}$;

- $(5,7)$ The absorption wavelengths around $900 \mathrm{~nm}$ and $1450 \mathrm{~nm}$ can be due to water content, and this can be residual water that can be related to porosity; 
- (6) Organic and hydroxyl bonds are associated with wavelengths around $1150 \mathrm{~nm}$;

- (8) Mineralogical clay compounds wavelengths around $2200 \mathrm{~nm}$ are needed to predict physical clay fraction;

- (9) around $2400 \mathrm{~nm}$ are wavelengths associated with some mineral hydroxyl bonds.

Areas 1-5 and 7-8 are used for the prediction of fine fractions, such as clays and silts, whereas areas 5-6 and 9 are related to coarser fractions (very fine and fine sand).

Most of the selected wavelengths (34 over 44) are in the VNIR range, but that does not imply that the SWIR selected wavelengths are not relevant, because they contain relevant particle size information. Furthermore, the use of only one of the two sensors, independently of the other, does not allow to obtain a performant model. If only the VNIR is used, the performances of prediction are lower than 0.9, and the uncertainty is slightly higher. The same applies to the SWIR with performance lower than 0.9 and an inversion of the grain size of laminae (in which coarse grains are predicted as fine grains). This shows the importance of combining sensors of several spectral ranges to improve modeling performances with complementary information.

\subsection{Prediction distribution}

The predicted PSD in Fig. 3d evidence the same three units than the reference PSD in Fig. 3b (unit I: $22 \mu \mathrm{m}$, unit II: 22-6 $\mu \mathrm{m}$ and unit III: $6 \mu \mathrm{m}$ ). The down-sampling of the predicted PSD in Fig. $3 \mathrm{c}$ allows for surface and volume analysis to be linked together with a correlation of $0.96(p<0.05)$ with the reference PSD. Two instantaneous deposits are quite visible at $14 \mathrm{~cm}$ and $16 \mathrm{~cm}$ depth through a marked drop in particle size.

The 50 models (one for each grain size class of PSD) allow estimation of the particle size fractions with the sum of the fine classes associated with the fractions according to the Wentworth scale 
(Wentworth, 1922). The correlation between the prediction maps of a single or several models and

240 the bias (difference of the predicted values) have been estimated (Table 3, Supplementary material 4). This shows that the coarser the particle size, the lower the correlation. Moreover, there is more bias for the silt fraction, which matches the observation of $r_{v / s}$ for the class between $6-10 \mu \mathrm{m}$. The $r_{v / s}$ is better for those estimated with a single model (Table 2), and the abundance maps (Supplementary material 4) seem to be smooth for those estimated from the predicted PSD.

\subsection{Sediment sources}

Five classes (EM) with their modes and abundances were estimated using the AnalySize function applied to the PSD prediction (Fig. 5a-c):

1. The first one (EM1) has a mode at $0.42 \mu \mathrm{m}$ (width at half height: $0.2-0.9 \mu \mathrm{m}$ ) and shows a decreasing abundance trend from the bottom to the top of the core, from $25 \%$ to $10 \%$.

The abundance maps in Fig. $6 \mathrm{~b}-\mathrm{f}$ show down and cross variations of the five pure classes. The two

2. The second (EM2) is centered at $4.19 \mu \mathrm{m}$ (width at half height: $1.44-12.21 \mu \mathrm{m}$ ). It has an upward decreasing trend from $62.5 \%$ to $5 \%$ and is mainly present below $25 \mathrm{~cm}$ depth and in instantaneous event deposits with values higher than $30 \%$.

3. The third (EM3) has a mode at $9.00 \mu \mathrm{m}$ (width at half height: $4.88-15.21 \mu \mathrm{m}$ ) and has an abundance quite stable at $10 \%$ except an increase at $15 \%$ in the instantaneous event.

4. The fourth (EM4) centered at $22.49 \mu \mathrm{m}$ (width at half height: $12.21-45.51 \mu \mathrm{m}$ ) is mainly present in the first $25 \mathrm{~cm}$ (eutrophic part) with an increasing upward trend from $5 \%$ to $30 \%$.

5. The fifth (EM5) has a mode at $65.51 \mu \mathrm{m}$ (width at half height: $26.2-150.0 \mu \mathrm{m}$ ) and is mainly present in the first $25 \mathrm{~cm}$ (eutrophic part) with an increasing upward trend from $5 \%$ to $25 \%$.

6. The residual part is mainly present in the two first units and has values lower than $2.5 \%$.

first (EM1-2) have the same variations and a high correlation of $0.99(p<0.05)$. They characterize 12 
unit III, i.e., the pre-eutrophication unit. Their trend along the core depth is the opposite of those of the two last (EM4-5) regardless of the proportions. EM4-5 are thus enriched in unit II and mostly unit I. The EM3 map is different with a quite homogeneous variation along the core except in specific lamina in the two first units. This end-member is also relatively abundant in the instantaneous event layer. The residual fraction (Fig. $6 \mathrm{~g}$ ) is more present in the laminated part of the core that might be explained by the presence of other sediment sources or a change in the size of previous sources.

\section{Discussion}

\subsection{Interpretation of the sources based on the laminae succession}

To interpret the end-members, we discuss a few laminae successions to see their compositions with the three main modes (EM2-3-4, Fig. 7) and to compare with previous descriptions of the laminae (Giguet-Covex et al., 2010) (Supplementary material 2). As presented in the lithological description, there are three different laminae, which are also well discriminated by the end-members (Fig. 7; Supplementary material 2. Based on PSD from the carbonated and decarbonated fractions of the sediments, Giguet-Covex et al. (2010) defined six classes corresponding to different sediment components. Five of these classes can be associated with the end-members determined in this study. EM4 agrees with the size range for large calcite crystals $(15-30 \mu \mathrm{m})$ and diatoms (30-45 $\mu \mathrm{m})$. EM3 reflecting small calcite crystals were characterized by a mode between $4.5 \mu \mathrm{m}$ and $8 \mu \mathrm{m}$ by GiguetCovex et al. (2010). EM2 fits well with the detrital particles previously defined with a mode between $6 \mu \mathrm{m}$ and $9 \mu \mathrm{m}$. EM1, which is highly correlated to EM2 $(0.99(p<0.05))$, was also observed but not discussed in the previous study (Giguet-Covex et al., 2010). This mode was only present in the carbonated PSD. We thus interpret it as representing micrite deposits. EM5 can be associated with a mix between diatom frustules and organic matter because it is highly correlated with EM4, which characterizes the spring lamina (i.e., the time of diatom bloom). 
Due to the predicted PSD range ( $0.15 \mu \mathrm{m}$ to $259 \mu \mathrm{m})$, two modes determined in the previous study cannot be estimated with hyperspectral data (OM: 150-350 $\mu \mathrm{m}$ and very large carbonate particles: 160-300 $\mu \mathrm{m})$. The modes are not the same due to the data used for their estimations. In GiguetCovex et al. (2010), PSD from the carbonated and decarbonated fractions of the sediments were used. Whereas in our study, we use the complete PSD that corresponds to a mix between the two fractions.

\subsubsection{Lamina counting}

The small calcite crystals (EM3; Fig. 7c), are quite localized and can be discriminated from the others. It is possible to enhance it with image processing. An abundance threshold is fixed at $40 \%$ to binarize the abundance map, in which upper values correspond to the EM3 deposit, and below this value to another one. A median filter is used to remove solitary points. Then, the lamina can be easily manually counted. They are correctly counted, until the year 1953, so 57 laminae can be discriminated. Before this, they are too fuzzy and thin. Also, the small calcite crystal abundance decreases lower than $40 \%$, and even a linear decreasing threshold allows with difficulty to discriminate this deposit because of laminae thinness.

\subsubsection{Estimation of the accumulation rate for each lamina}

The accumulation rate of each lamina can be estimated if the first pixel of each year is determined. The EM2-3-4 maps were reduced to a median signal along the depth, the EM4 trend shows fluctuations that can allow the beginning of the year to be identified. Unfortunately, it is too variable to use automatic detection, so manual selections were made. Then, each pixel is associated with one of the three laminae based on their EM percentage. Because the spring and summer laminae are related to the same compounds (EM3-4) that overlap spatially, a rule based on the EM3-4 values is proposed to separate them. If the value of the EM3 is greater than $40 \%$ of the EM4 one, then the 
corresponding lamina is summer, otherwise, it is the spring. There is not this kind of problem with the winter lamina (EM2). Finally, this classification signal is used to count the number of pixels of each season in a year to estimate accumulation rates for each lamina (Fig. $7 \mathrm{f}$ and 8).

Fig. $8 c$ shows an increase in diatom and large calcite crystal accumulations until 1982 , followed by a decrease. These components reflect primary productivity. Consequently, a decrease after 1982 indicates an improvement in trophic status, which is in agreement with the decrease in phosphorus supplies presented in Jenny et al. (2013). The small calcite crystal accumulation rate has an opposite trend relative to the large calcite crystals and diatoms (Fig. 8b). This can also be explained by changes in trophic status. Eutrophication favors the precipitation of large calcite crystals compared to smaller ones. The accumulation rate of detrital particles (Fig. 8a) represents annual inputs from the Rhône River floods to the lake. The peak in 1990 represents the large floods of February 1990 (Jenny et al., 2014).

\subsubsection{Visible and near-infrared spectra of each lamina}

The three laminae, the instantaneous events and unit III were manually selected to find their pixels and then to extract their average spectral signatures (Fig. 9). The continuum removed (Clark and

Roush, 1984) of the spectra allows for them to be normalized to compare the absorption spectra. It allows us to see five spectral ranges, which have different contributions in the different units and facies:

- The carotenoids and or iron oxides are mostly present in the laminated unit, in all the laminae.

- The chlorophyll pigments are mostly present in the spring and summer lamina and indicate the increase in lacustrine productivity due to eutrophication. 
- The organic and hydroxyl compounds are higher in the summer and winter laminae as well as in the instantaneous events. This result is interpreted as reflecting lacustrine and terrestrial organic matter.

- The water content shows a gradient, from the lowest to the highest: non-eutrophic part, instantaneous event, winter, spring, summer laminae. This can be associated to residual water linked to porosity and compaction.

\subsection{Detection of a sub-unit}

The high resolution of analysis allows us to observe the trends with high precision and detect similar groups of trends for unit characterization. The Bourget core was divided into three units, but based on our evidence unit I was split into two sub-units, from 0 to $6 \mathrm{~cm}$ depth (2009-1992, unit $\mathrm{l}_{\mathrm{a}}$ ) and from 6 to $18 \mathrm{~cm}$ (1992-1962, unit $\left.\mathrm{I}_{\mathrm{b}}\right)$. The main observed changes in unit I are:

- A decrease of particle size in the PSD (Fig. 3d) that corresponds to an increase in small bioinduced calcite crystals, a decrease of large calcite crystals and diatom frustules (Fig. 5c and $6 d-e)$,

- An increase in the residual part (Fig. $6 \mathrm{~g}$ ) that can be induced by modification of the environment.

The changes in this sub-unit can reflect the response of the lake to restoration programs, especially the diversion of treated waste-waters into the Rhône river in the 1990s that improved water quality and changed the biochemistry of the lake (Jacquet et al., 2005; Berthon et al., 2014).

\subsection{Possibilities of the hyperspectral analysis}

The use of high-resolution analysis, such as hyperspectral imaging, to estimate PSD associated with unmixing methods shows great possibilities to infer the provenance of the material and their 16 
transport, as well as some deposition processes (floods, landslide, eruption). And also their variations across times, with changes in the population of diatoms or other organisms, changes in the physicalchemistry of the lake or the watershed or beyond.

Hyperspectral imaging is a very informative tool which can be used for more than particle size studies. This method has already proved useful for the prediction of organic matter (Van Exem et al., 2018; Jacq et al., 2019b), pigments (Schneider et al., 2018), and to perform source to sink analysis (Van Exem et al., 2019). Some proxies can be estimated directly after HSI acquisition, and other proxies need to process the data with or without destructive analysis.

A Matlab toolbox was created for the study of particle size presented in this paper and for a previous study of organic matter (Jacq et al., 2019b), and also allows for the generation of models for organic matter (LOI550 and RockEval) and particle size on several lakes (unpublished works). This toolbox can be found at https://github.com/JacqKevin/HSI_PLSR, developed with Matlab R2018a (the Parallel Computing Toolbox can be used for faster calculations). It contains functions to create a PLSR model and to apply it to the data, and also spectral preprocessing and variable selection algorithms. The regular use of this toolbox allows for highlighting precautions and difficulties related to data. The destructive data used to calibrate the models need to be representative of the main variations observed in the sample. The creation of an optimal predictive model requires to have variability inside the destructive analysis values. Future works will focus on the determination of relevant sampling areas for a proxy using only hyperspectral data. There are also the sediment matrix effects with the presence of several different lithologies that can disturb the modeling.

\section{Conclusions}

Hyperspectral imaging, with its spatial and spectral dimensions, is a very informative analytical method. This method promises great possibilities because it offers high resolution $(200 \mu \mathrm{m})$, is non17 
destructive and fast ( $15 \mathrm{~min}$ for a $1.5 \mathrm{~m}$ core for each sensor). In this study, HSI allows estimation of particle size distribution and size fraction in each point of the lake Bourget core. Then, with an unmixing method, five sediment sources were estimated and characterized in a previous study on this lake. The high spatial resolution allowed discrimination of three laminae. With image processing methods, they were discretized to estimate their spectral signatures and thus their chemistry. They were also manually counted, and that agreed with the age model. Therefore, hyperspectral imaging for the prediction of PSD and characterization of end-members, as well as their annual accumulation rates, is very useful for the study of sediment cores and environmental samples.

Some improvements are needed for the extraction of a relevant number of end-members in this data. Sequential extraction of end-members with the study of residuals seems to be relevant because the existing algorithms find only the main ones. Further works using the spatio-spectral approaches can improve the relevance of the estimated PSD, the fine particles can be estimated with the spectral dimension and the coarse ones with the spatial dimensions

\section{Acknowledgements}

The Bourget core used in this study is stored in the EDYTEM laboratory that also performed the PSD analysis in 2009 during the IPER-RETRO program (ANR-08-VUL 005). The hyperspectral imaging acquisition was made at the University of Normandie-Rouen and was funded by the Region Normandie, which supports the scientific consortium SCALE UMR CNRS 3730. Furthermore, we thank the anonymous reviewer and Jasper Knight (Editor-in-Chief) for their helpful comments. 
Arnaud, F., Revel, M., Chapron, E., Desmet, M., Tribovillard, N., 2005. 7200 years of Rhône river flooding activity in Lake Le Bourget, France: a high-resolution sediment record of NW Alps hydrology. The Holocene 15, 420-428.

Arnaud, F., Révillon, S., Debret, M., Revel, M., Chapron, E., Jacob, J., Giguet-Covex, C., Poulenard, J., Magny, M., 2012. Lake Bourget regional erosion patterns reconstruction reveals Holocene NW European Alps soil evolution and paleohydrology. Quaternary Science Reviews 51, 81-92.

Berthon, V., Alric, B., Rimet, F., Perga, M.-E., 2014. Sensitivity and responses of diatoms to climate warming in lakes heavily influenced by humans. Freshwater Biology 59, 1755-1767.

Butz, C., Grosjean, M., Fischer, D., Wunderle, S., Tylmann, W., Rein, B., 2015. Hyperspectral imaging spectroscopy: a promising method for the biogeochemical analysis of lake sediments. Journal of Applied Remote Sensing 9, 1-20.

Butz, C., Grosjean, M., Goslar, T., Tylmann, W., 2017. Hyperspectral imaging of sedimentary bacterial pigments: a 1700-year history of meromixis from varved Lake Jaczno, northeast Poland. Journal of Paleolimnology 1-16.

Casa, R., Castaldi, F., Pascucci, S., Palombo, A., Pignatti, S., 2013. A comparison of sensor resolution and calibration strategies for soil texture estimation from hyperspectral remote sensing. Geoderma 197-198, 17-26.

Ce Liu, Yuen, J., Torralba, A., 2011. SIFT Flow: Dense Correspondence across Scenes and Its Applications. IEEE Transactions on Pattern Analysis and Machine Intelligence 33, 978-994.

Clark, R.N., Roush, T.L., 1984. Reflectance spectroscopy: Quantitative analysis techniques for remote 
de Santana, F.B., de Souza, A.M., Poppi, R.J., 2018. Visible and near infrared spectroscopy coupled to random forest to quantify some soil quality parameters. Spectrochimica Acta - Part A: Molecular and Biomolecular Spectroscopy 191, 454-462.

Debret, M., Chapron, E., Desmet, M., Rolland-Revel, M., Magand, O., Trentesaux, A., Bout-

Demattê, J.A.M., Alves, M.R., Gallo, B.C., Fongaro, C.T., Souza, A.B., Romero, D.J., Sato, M.V., 2015. 
Jacq, K., Coquin, D., Fanget, B., Perrette, Y., Debret, M., 2019a. Study of pansharpening methods applied to hyperspectral images of sediment cores, in: 2019 22nd International Conference on Information Fusion (FUSION) (FUSION 2019). Ottawa, Canada.

Jacq, K., Perrette, Y., Fanget, B., Sabatier, P., Coquin, D., Martinez-Lamas, R., Debret, M., Arnaud, F., 2019b. High-resolution prediction of organic matter concentration with hyperspectral imaging on a sediment core. Science of the Total Environment 663, 236-244.

Jacquet, S., Briand, J.-F., Leboulanger, C., Avois-Jacquet, C., Oberhaus, L., Tassin, B., Vinçon-Leite, B., Paolini, G., Druart, J.-C., Anneville, O., Humbert, J.-F., 2005. The proliferation of the toxic cyanobacterium Planktothrix rubescens following restoration of the largest natural French lake (Lac du Bourget). Harmful Algae 4, 651-672.

Jenny, J.-P., 2013. Réponses des grands lacs périalpins aux pressions anthropiques et climatiques récentes : reconstitutions spatio-temporelles à partir d'archives sédimentaires. HAL. Université Grenoble Alpes.

Jenny, J.-P., Arnaud, F., Dorioz, J.-M., Covex, C.G., Frossard, V., Sabatier, P., Millet, L., Reyss, J.-L., Tachikawa, K., Bard, E., Pignol, C., Soufi, F., Romeyer, O., Perga, M.-E., 2013. A spatiotemporal investigation of varved sediments highlights the dynamics of hypolimnetic hypoxia in a large hard-water lake over the last 150 years. Limnology and Oceanography 58, 1395-1408.

Jenny, J.-P., Wilhelm, B., Arnaud, F., Sabatier, P., Giguet Covex, C., Mélo, A., Fanget, B., Malet, E., Ployon, E., Perga, M.E., 2014. A 4D sedimentological approach to reconstructing the flood frequency and intensity of the Rhône River (Lake Bourget, NW European Alps). Journal of Paleolimnology 51, 469-483. 
Nanni, M.R., Cezar, E., Silva Junior, C.A. da, Silva, G.F.C., da Silva Gualberto, A.A., 2018. Partial least squares regression (PLSR) associated with spectral response to predict soil attributes in transitional lithologies. Archives of Agronomy and Soil Science 64, 682-695.

Nouri, M., Gomez, C., Gorretta, N., Roger, J.M., 2017. Clay content mapping from airborne hyperspectral Vis-NIR data by transferring a laboratory regression model. Geoderma 298, 5466.

Paterson, G.A., Heslop, D., 2015. New methods for unmixing sediment grain size data. Geochemistry, Geophysics, Geosystems 16, 4494-4506.

Perga, M.-E., Frossard, V., Jenny, J.-P., Alric, B., Arnaud, F., Berthon, V., Black, J.L., Domaizon, I., Giguet-Covex, C., Kirkham, A., Magny, M., Manca, M., Marchetto, A., Millet, L., Paillès, C., Pignol, C., Poulenard, J., Reyss, J.-L., Rimet, F., Sabatier, P., Savichtcheva, O., Sylvestre, F., Verneaux, V., 2015. High-resolution paleolimnology opens new management perspectives for lakes adaptation to climate warming. Frontiers in Ecology and Evolution 3, 72.

Van Exem, A., Debret, M., Copard, Y., Vannière, B., Sabatier, P., Marcotte, S., Laignel, B., Reyss, J.-L., Desmet, M., 2018. Hyperspectral core logging for fire reconstruction studies. Journal of Paleolimnology 59, 297-308.

van Hateren, J.A., Prins, M.A., van Balen, R.T., 2017. On the genetically meaningful decomposition of grain-size distributions: A comparison of different end-member modelling algorithms. Sedimentary Geology 375, 49-71.

Viscarra Rossel, R.A., Behrens, T., 2010. Using data mining to model and interpret soil diffuse reflectance spectra. Geoderma 158, 46-54.

Viscarra Rossel, R.A., Behrens, T., Ben-Dor, E., Brown, D.J., Demattê, J.A.M., Shepherd, K.D., Shi, Z., 

Stenberg, B., Stevens, A., Adamchuk, V., Aïchi, H., Barthès, B.G., Bartholomeus, H.M., Bayer, A.D., Bernoux, M., Böttcher, K., Brodsky, L., Du, C.W., Chappell, A., Fouad, Y., Genot, V., Gomez, C., Grunwald, S., Gubler, A., Guerrero, C., Hedley, C.B., Knadel, M., Morràs, H.J.M., Nocita, M., Ramirez-Lopez, L., Roudier, P., Campos, E.M.R., Sanborn, P., Sellitto, V.M., Sudduth, K.A., Rawlins, B.G., Walter, C., Winowiecki, L.A., Hong, S.Y., Ji, W., 2016. A global spectral library to characterize the world's soil. Earth-Science Reviews.

Wentworth, C.K., 1922. A Scale of Grade and Class Terms for Clastic Sediments. The Journal of Geology 30, 377-392.

Wetzel, D.L., 1983. Near-infrared reflectance analysis. Analytical Chemistry 55, 1165A-1176A.

Wold, S., Ruhe, A., Wold, H., Dunn, III, W.J., 1984. The Collinearity Problem in Linear Regression. The Partial Least Squares (PLS) Approach to Generalized Inverses. SIAM Journal on Scientific and Statistical Computing 5, 735-743.

Yu, S.-Y., Colman, S.M., Li, L., 2016. BEMMA: A Hierarchical Bayesian End-Member Modeling Analysis of Sediment Grain-Size Distributions. Mathematical Geosciences 48, 723-741.

Żarczyński, M., Szmańda, J., Tylmann, W., Żarczyński, M., Szmańda, J., Tylmann, W., 2019. Grain-Size Distribution and Structural Characteristics of Varved Sediments from Lake Żabińskie (Northeastern Poland). Quaternary 2, 1-15.

Zhang, X., Zhou, A., Wang, X., Song, M., Zhao, Y., Xie, H., Russell, J.M., Chen, F., 2017. Unmixing grainsize distributions in lake sediments: a new method of endmember modeling using hierarchical clustering. Quaternary Research 1-9. 


\section{Figures}

Fig. 1. (a) Location and the catchment area of Lake Bourget. (b) Bathymetry, tributaries and effluents of the lake with the coring site.

Fig. 2. (a) Image RGB of the core, (b) lithology (with three units and flood deposits), (c) particle size fractions (in \%) by the laser granulometer and (d) average predicted particle size fractions (in \%) by the hyperspectral imaging.

Fig. 3. (a) Image RGB of the core, (b) PSD (in \%) of the laser granulometer, (c) predicted PSD (in \%) subsampled at the sampling resolution $(5 \mathrm{~mm})$, and (d) high-resolution predicted PSD (in \%) by the hyperspectral imaging.

Fig. 4. Selected wavelengths and associated compound areas for the five models (four fractions and the complete PSD) in the visible range on the left, the near-infrared range on the right and a gap between them in the grey area.

Fig. 5. (a) The five end-members estimated with the predicted PSD by HSI, (b) image RGB of the core, (c) profiles of the five sources (1-5) and the residual part (6) estimated with the averaged of the EM maps along depth (in \%).

Fig. 6. (a) Image RGB of the core, (b-f) the abundance maps of the five end-members estimated by AnalySize and (g) the residual fraction (in \%).

Fig. 7. (a) Image RGB of a laminated area, (b-d) the three main end-members abundance maps (EM43-2 in \%), (e) schematic succession of the lamina; (f) estimation of the annual accumulation source rates (in $\mathrm{mm} /$ year).

Fig. 8. Estimation of the annual lamina accumulation rates for (a) detrital particles, (b) small calcite crystals, (c) diatoms frustules associated with large calcite crystals. 
525 Fig. 9. (a) Visible and near-infrared signatures and (b) continuum removal with associated main

526 absorptions of the three laminae (spring, summer, winter), an instantaneous event and the non-

527 eutrophic part.

528 


\section{Tables}

530

531 Table 1. Hyperspectral sensor properties

532 Table 2. Statistics of the reference data and models performances (number of latent variables (LV)

533 and of selected wavelengths ( $w \mathrm{l})$, calibration and validation correlations ( $r_{\text {cal }}$ and $\left.r_{\text {val }}\right)$, uncertainty

534 (Unc), volume-surface correlation $\left.\left(r_{v / s}\right)\right)$ for the four particle size fractions and the averaged of the

535 fifty classes of the PSD.

536 Table 3. Correlation and bias between the abundance maps of the particle size fractions estimated by

537 their PLSR models or with the PSD prediction; volume-surface correlation of the map estimated with

538 the PSD prediction.

539 


\section{Supplementary materials}

541 Supplementary material 1. Correlations of the sediment cores use for our (LDB09_P101) and Giguet

542 (LDB06_P2) studies (Giguet-Covex et al., 2010)

543 Supplementary material 2. Thin section of the LDB06_P2 core used for the Ca, Al and Si counts by

544 micro-XRF.

545 Supplementary material 3. Correlation coefficients of the PSD models in calibration, validation and

546 for $r v / s$.

547 Supplementary material 4. Abundance maps of the particle size fractions estimated with their models

548 (single, a-c-e-g) or with the predicted PSD (multiple, b-d-f-h) (in \%). 


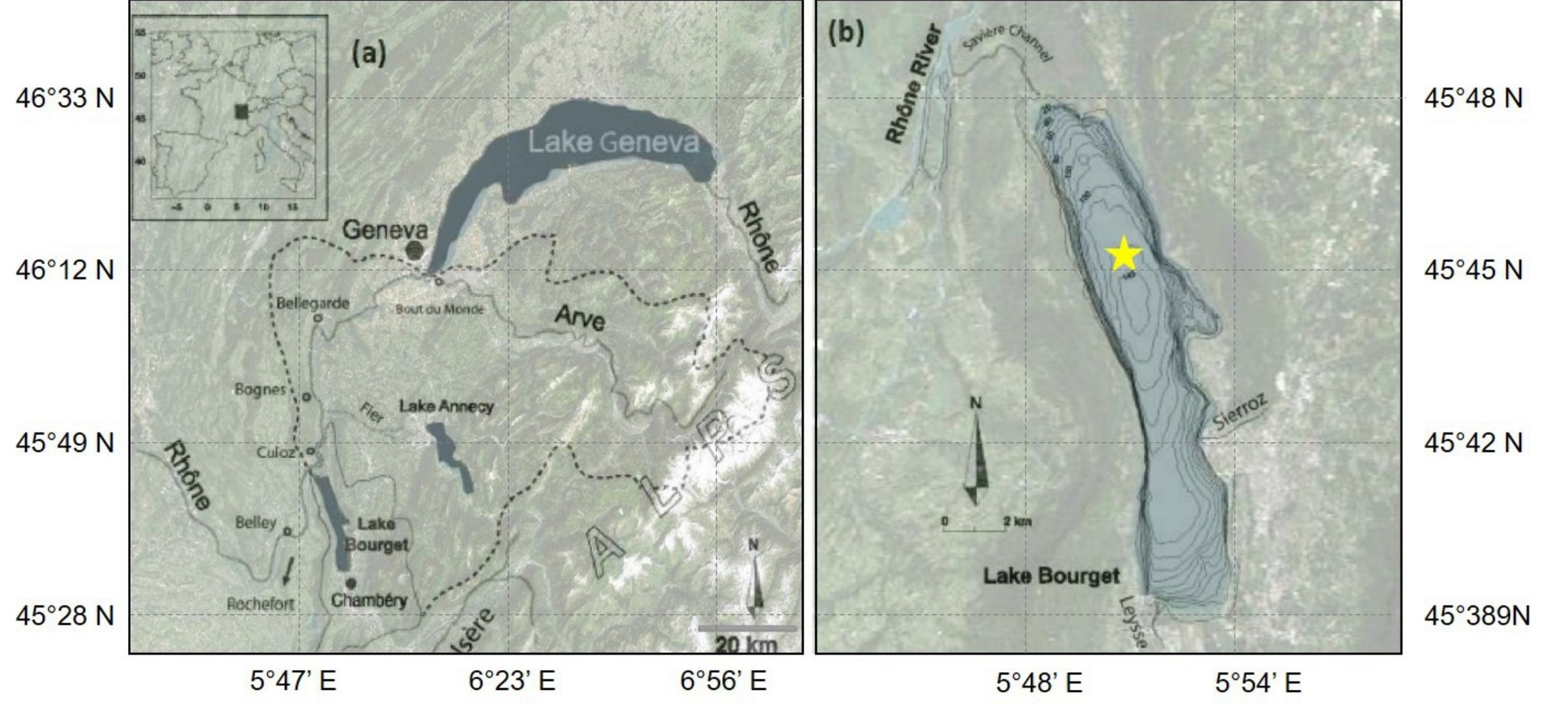


(a)

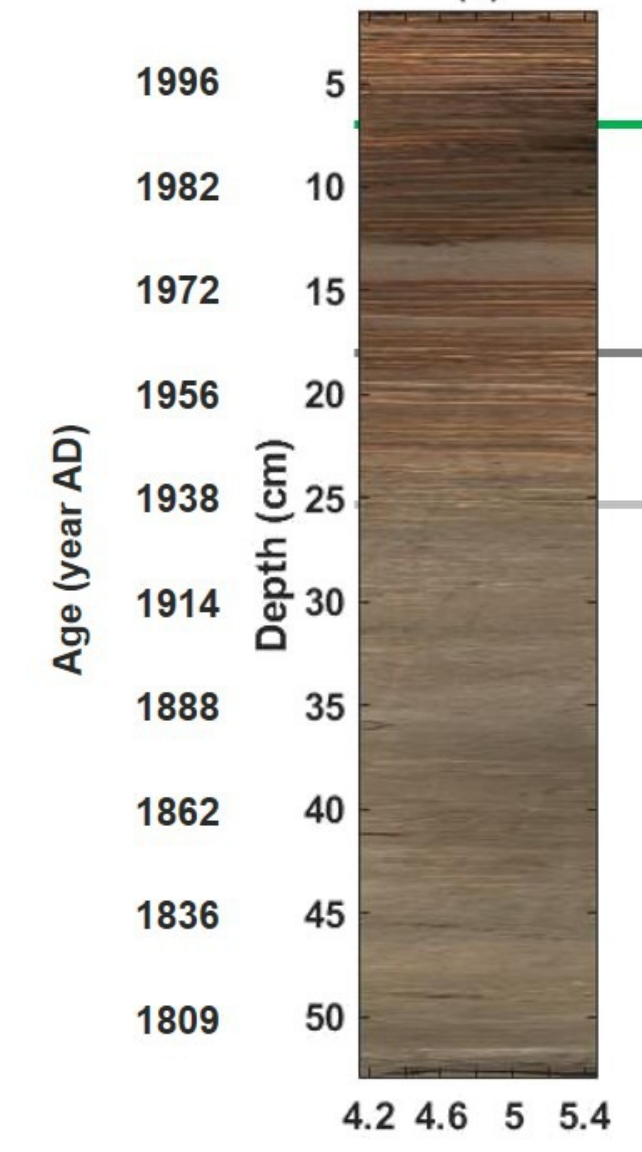

Width (cm) (b)

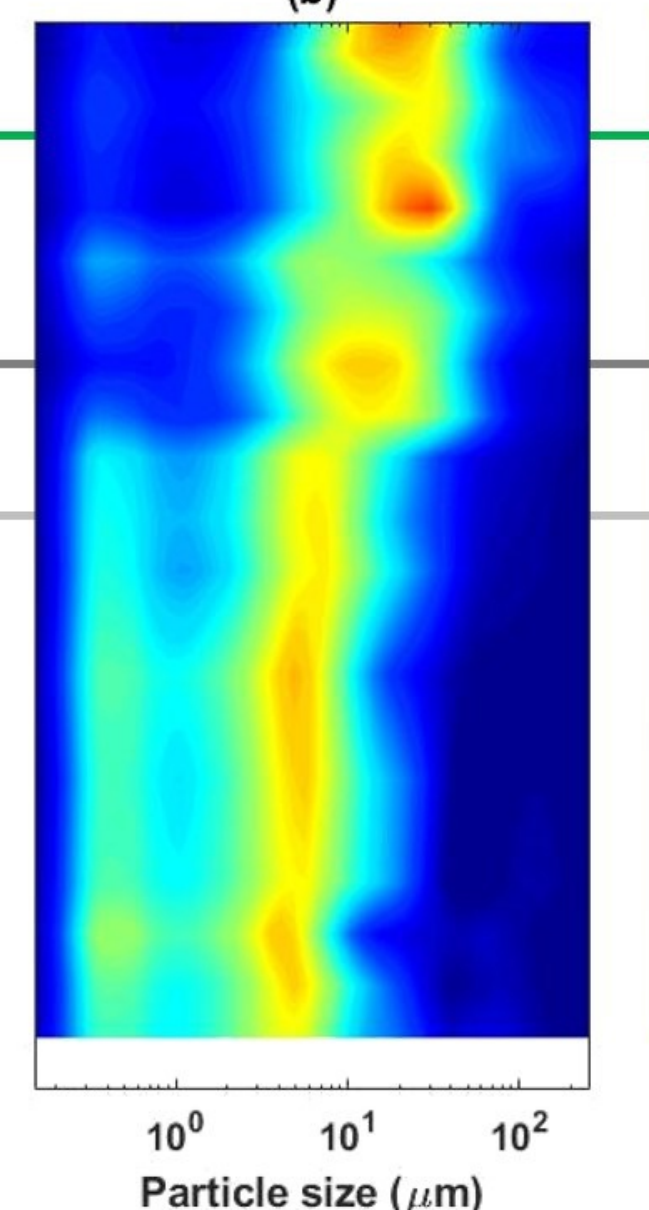

Particle size $(\mu \mathrm{m})$ (c)

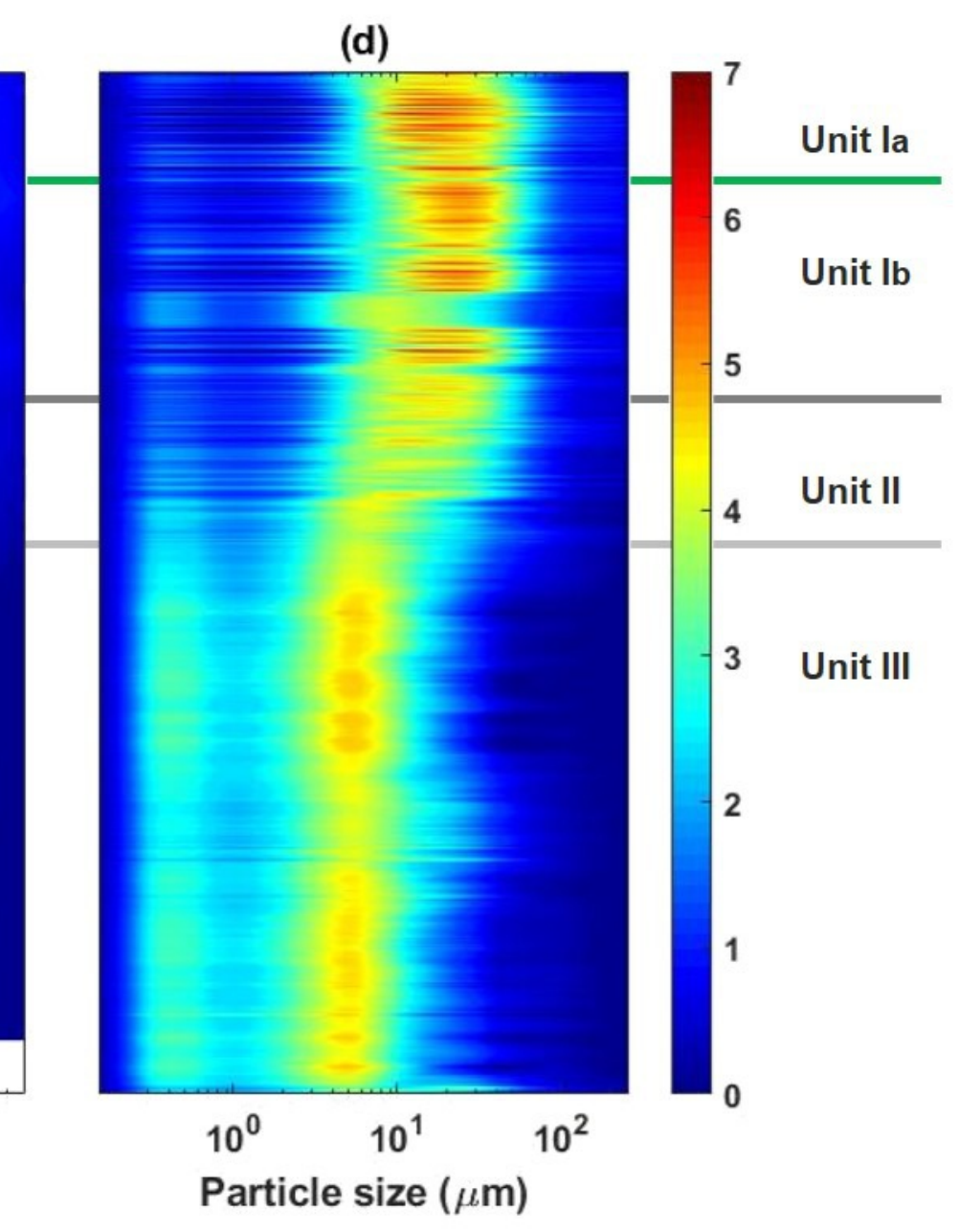




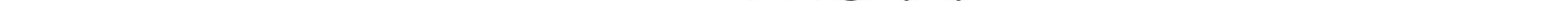




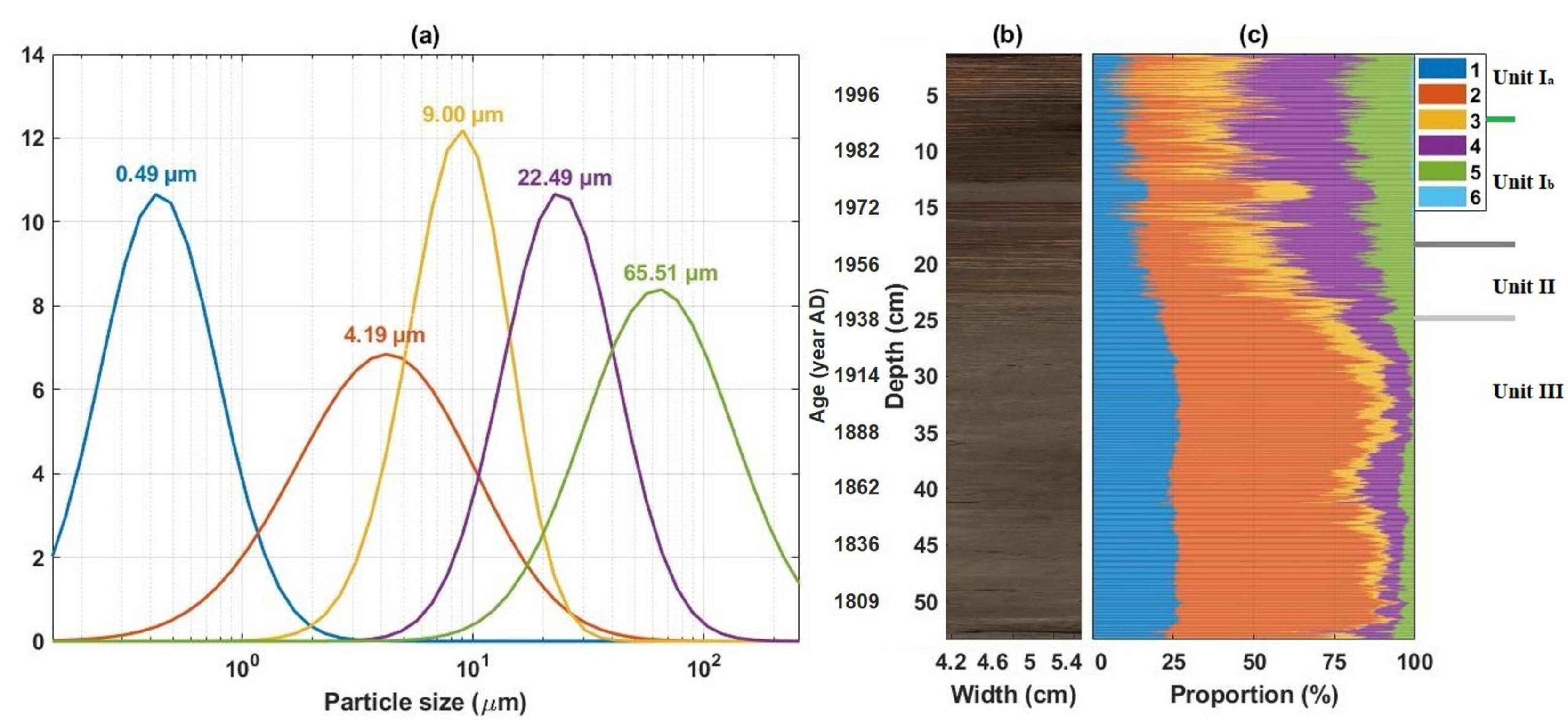


(a)

(b)

EM1 $0.49 \mu \mathrm{m}$ (c)

EM2 (d)

EM3

$9.00 \mu \mathrm{m}$

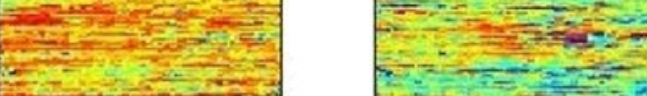

1982

10

1972

1956

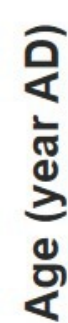

(c)

1938 हु 1914 $1888 \quad 35$

1862

1836

1809

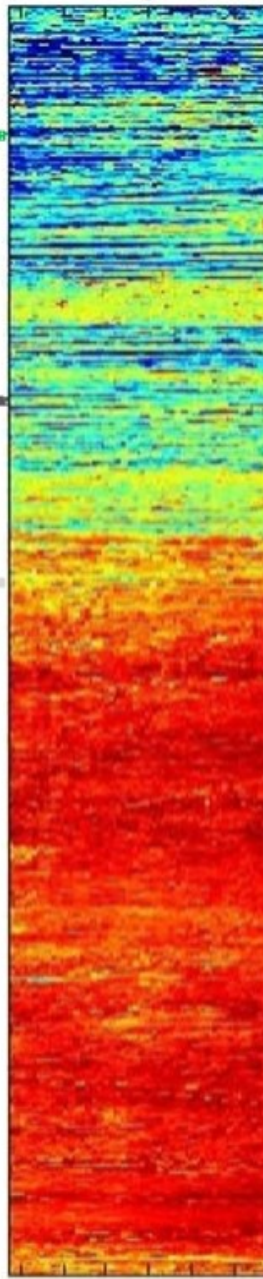

$\begin{array}{llll}4.2 & 4.6 & 5 & 5.4\end{array}$ Width $(\mathrm{cm})$

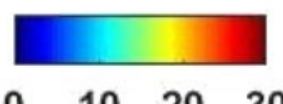

$\begin{array}{llll}4.2 & 4.6 & 5 & 5.4\end{array}$ Width (cm)

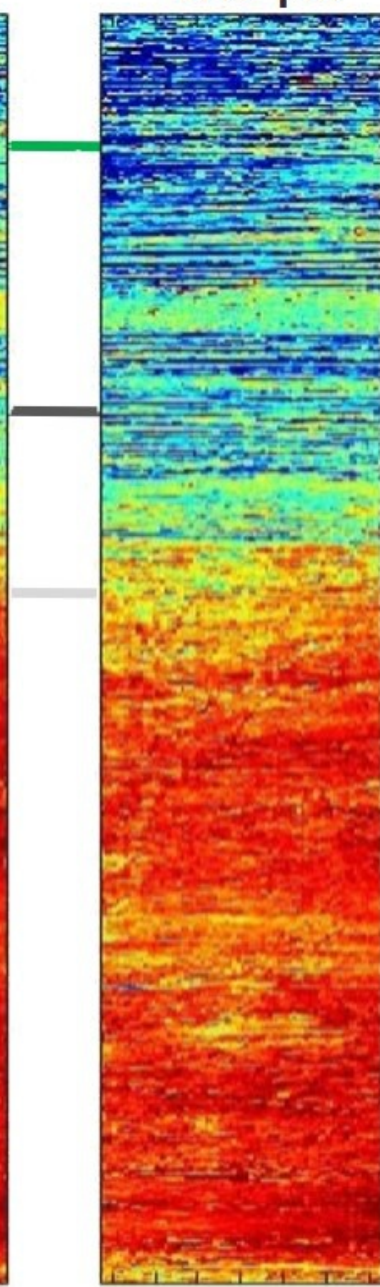

$\begin{array}{llll}4.2 & 4.6 & 5 & 5.4\end{array}$
Width (cm)

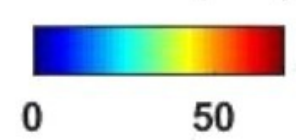

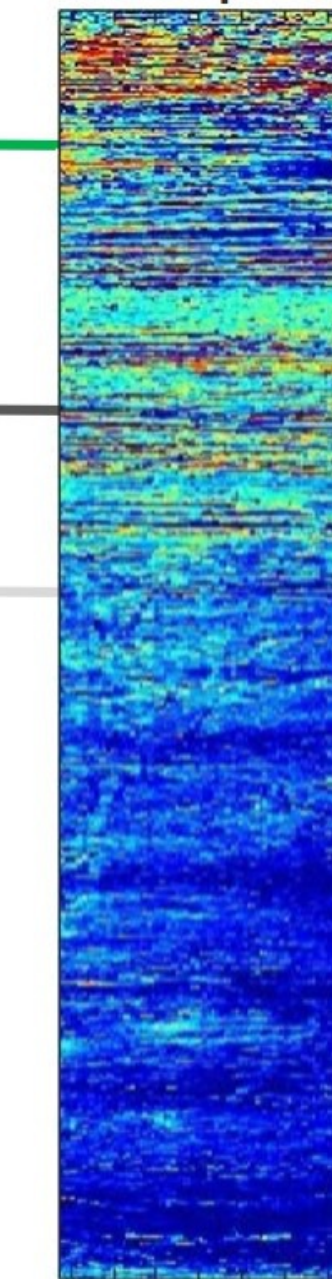

$\begin{array}{llll}4.2 & 4.6 & 5 & 5.4\end{array}$ Width (cm)

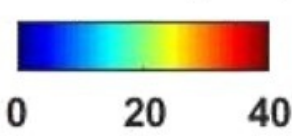

(e)

(e) EM4

$22.49 \mu \mathrm{m} \quad 65.51 \mu \mathrm{m}$
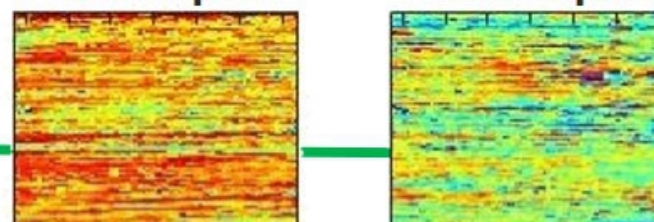

(f)

(g)

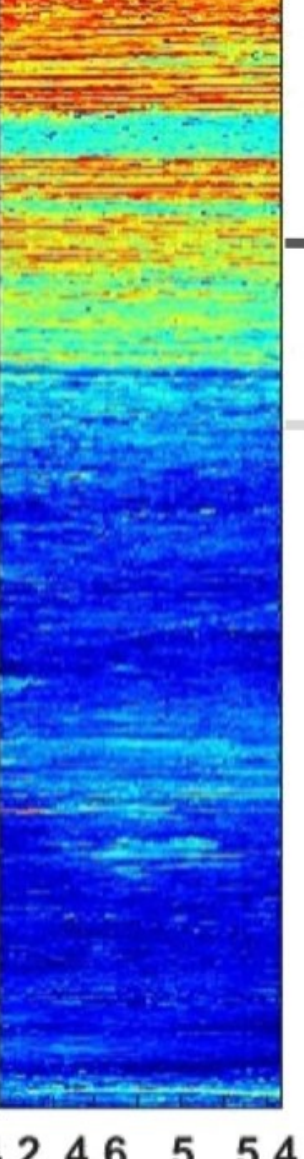

Width $(\mathrm{cm})$

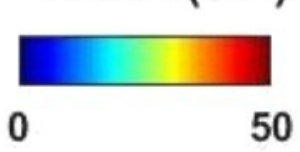

Residual

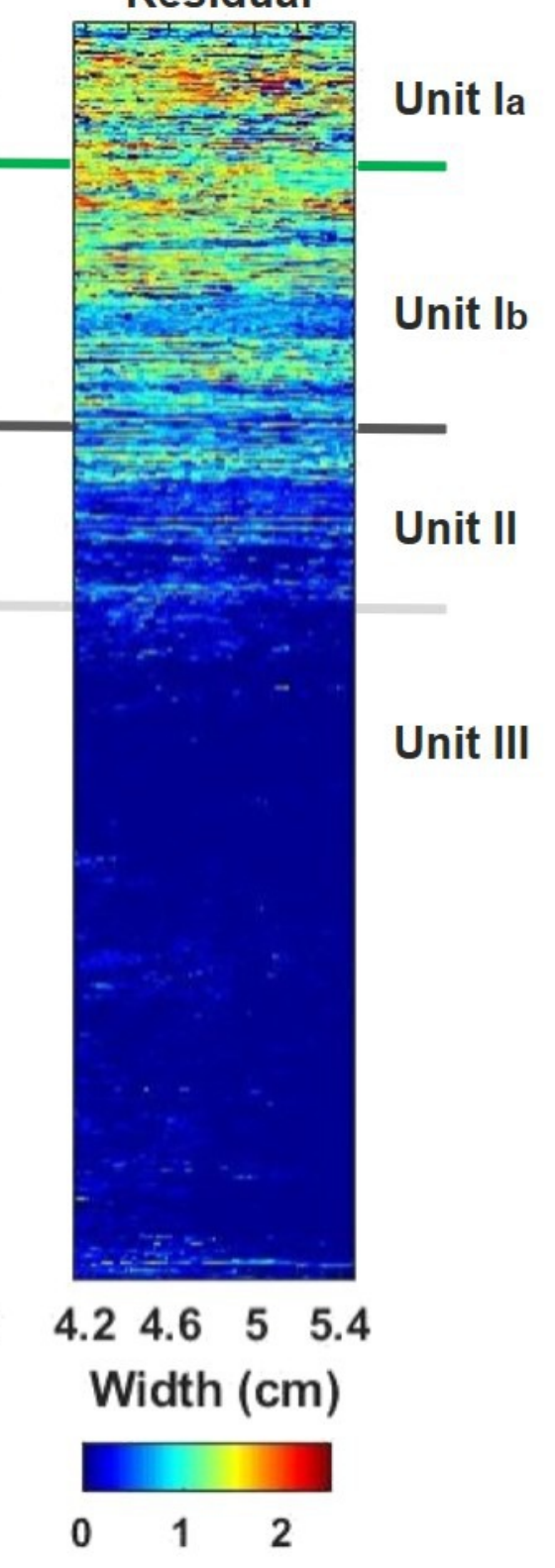


(a)

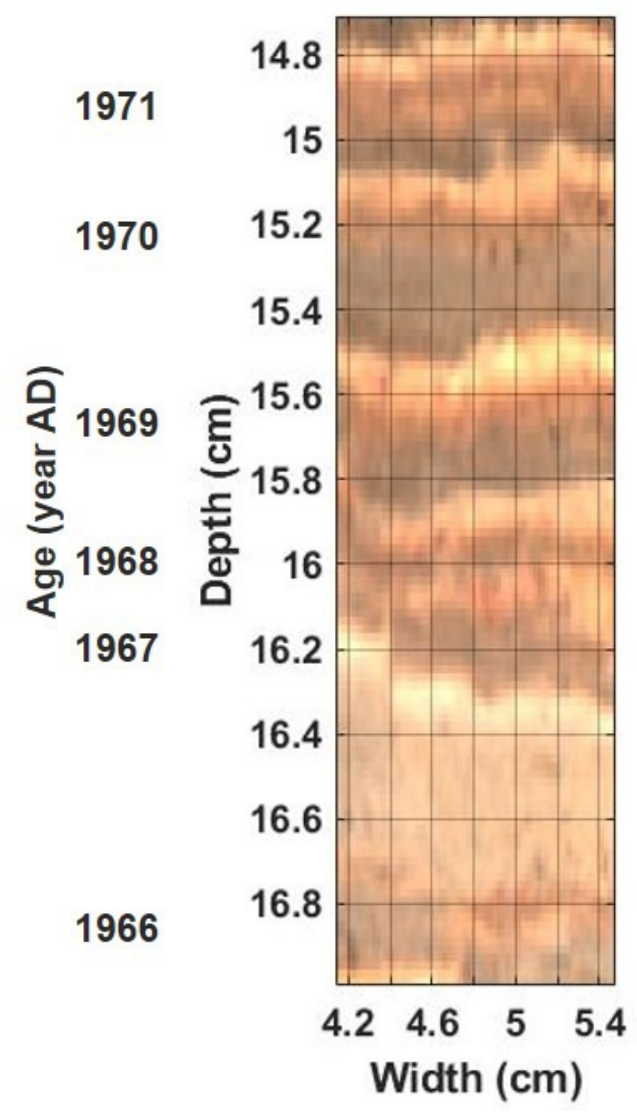

(b) EM4 Diatoms +

(c) EM3

Large calcite

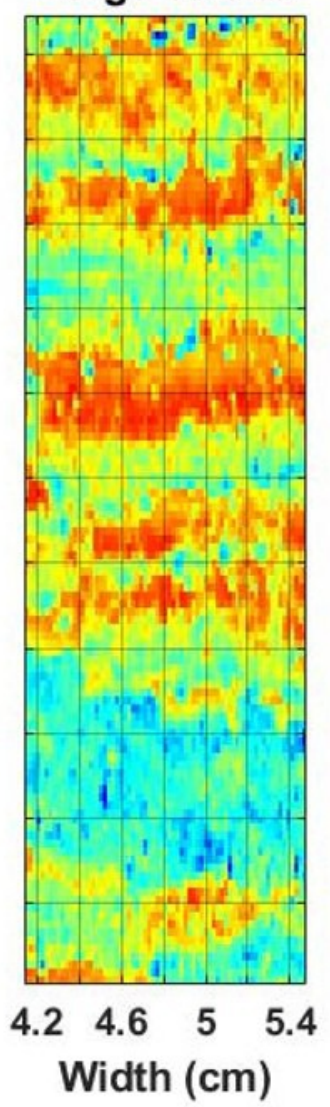

(d) EM2

(e)

Small calcite

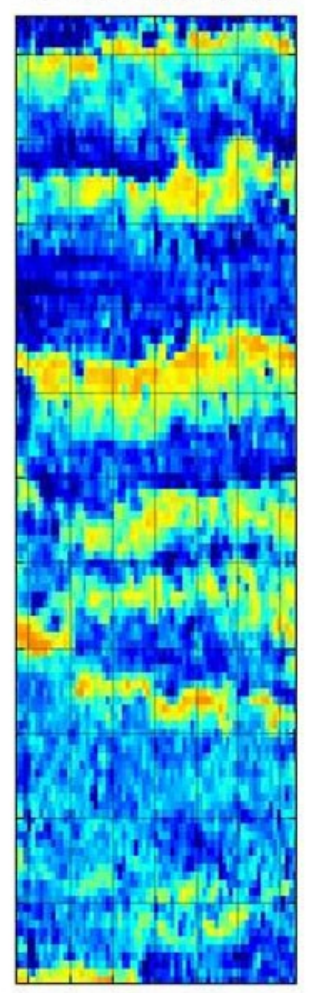

$\begin{array}{llll}4.2 & 4.6 & 5 & 5.4\end{array}$ Width (cm)

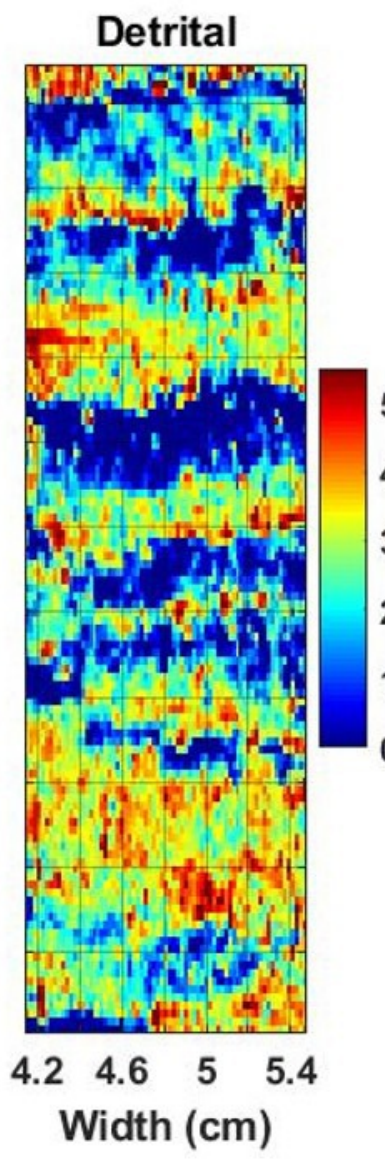

(f)

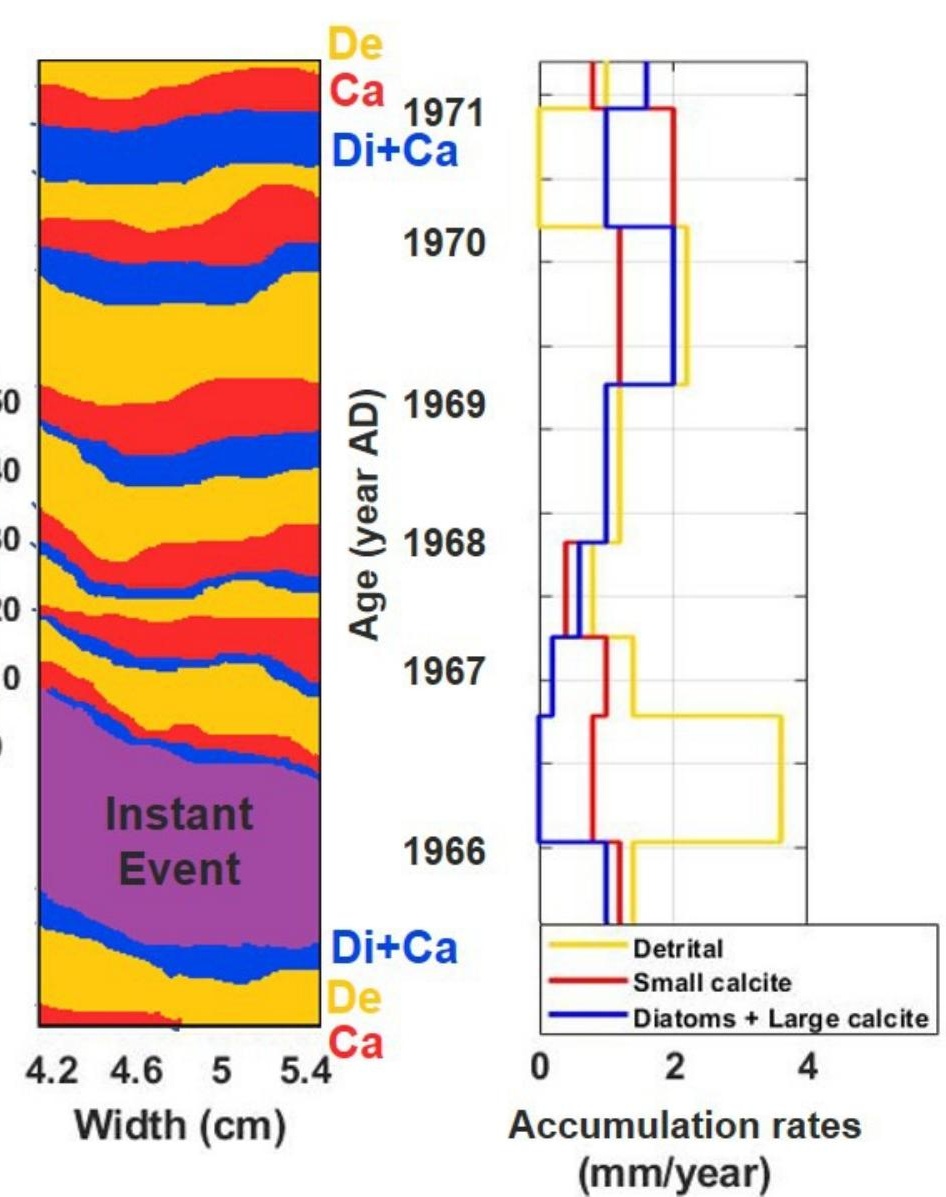




\section{(a) Detrital}

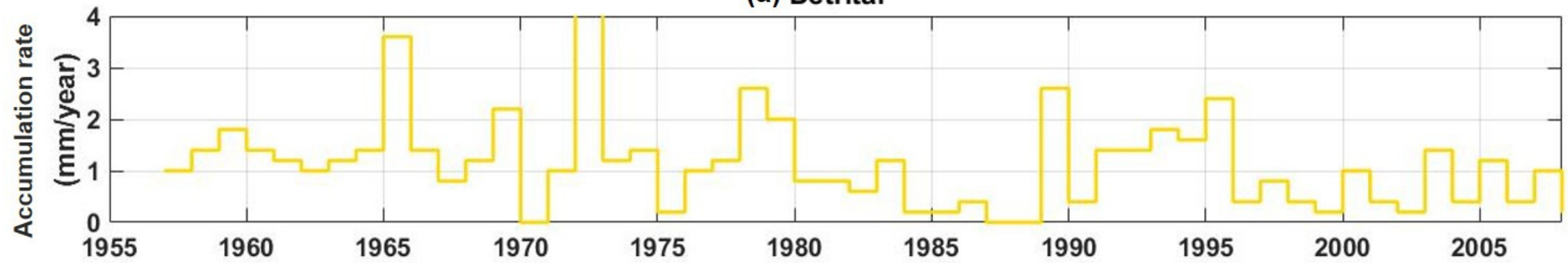

(b) Small calcite

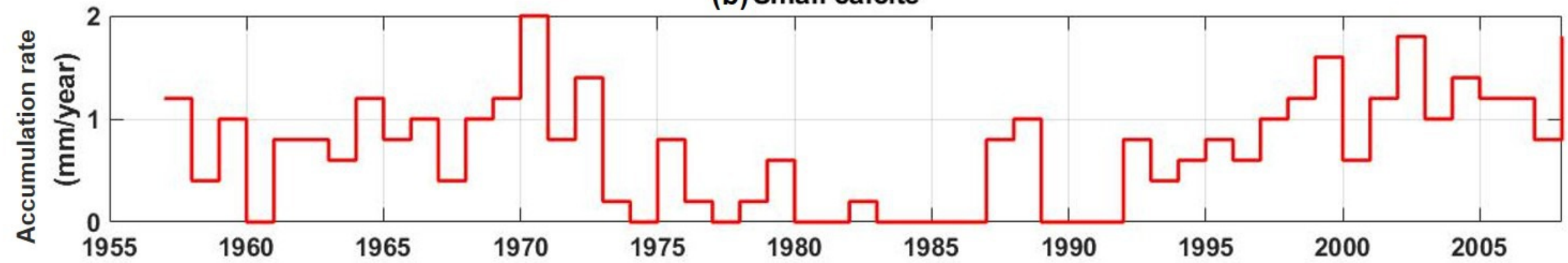

(c) Diatoms + large calcite

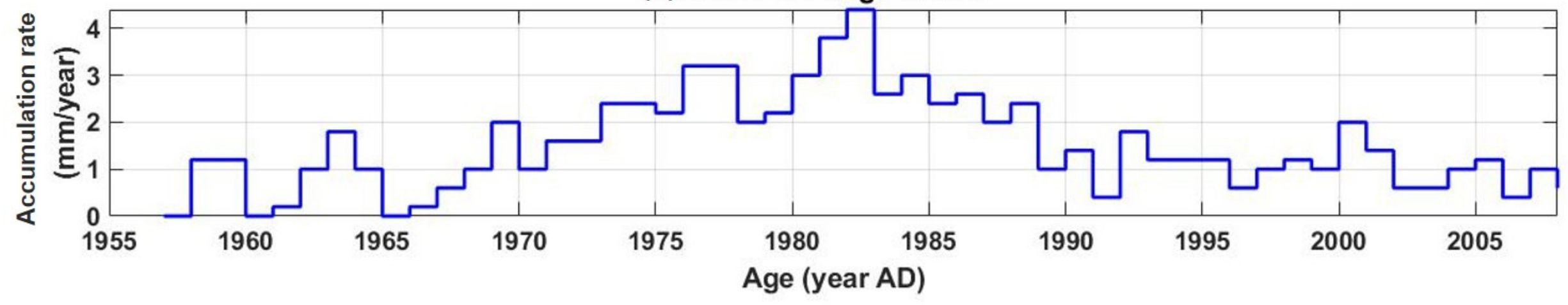


(a)

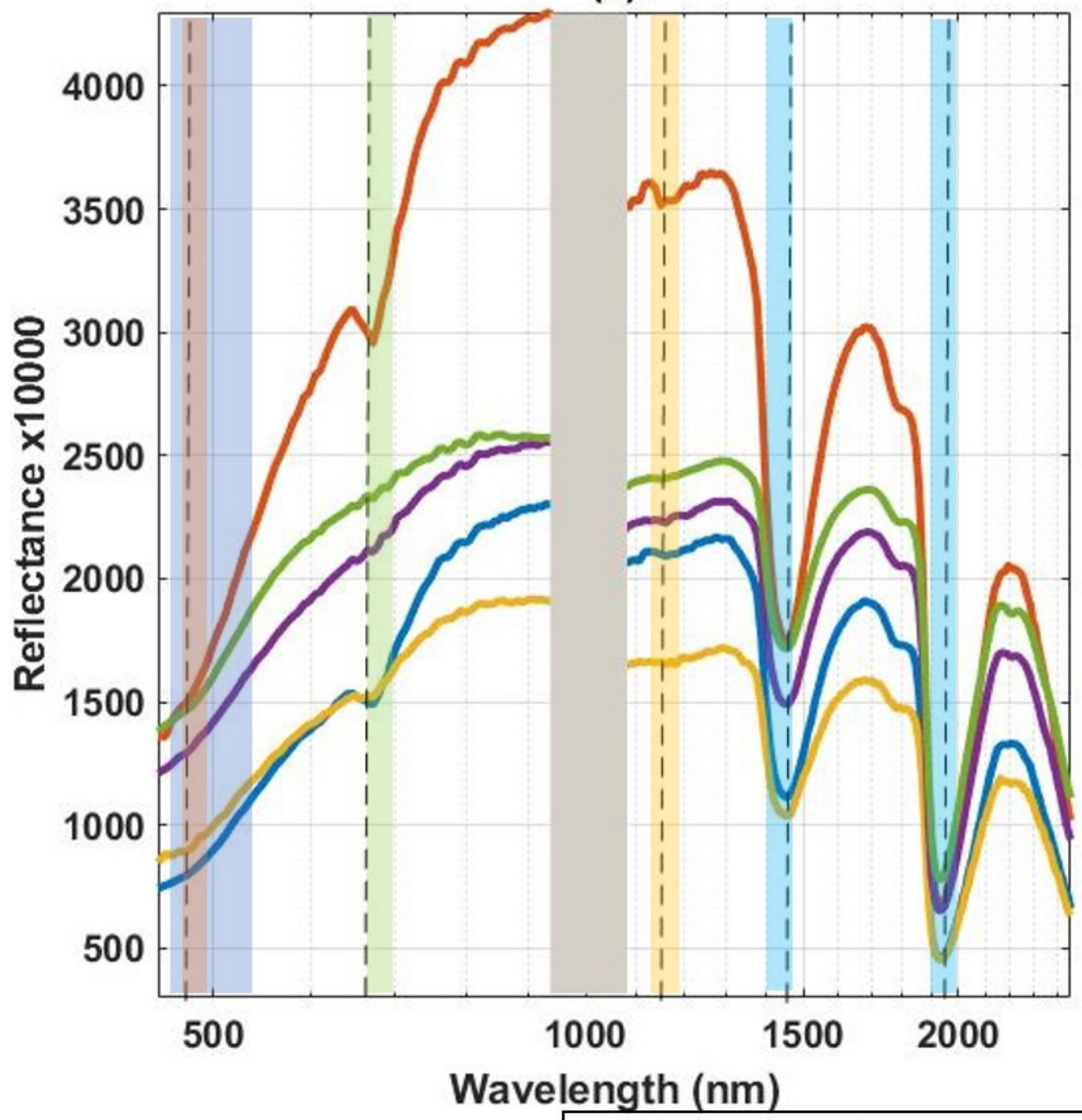

(b)

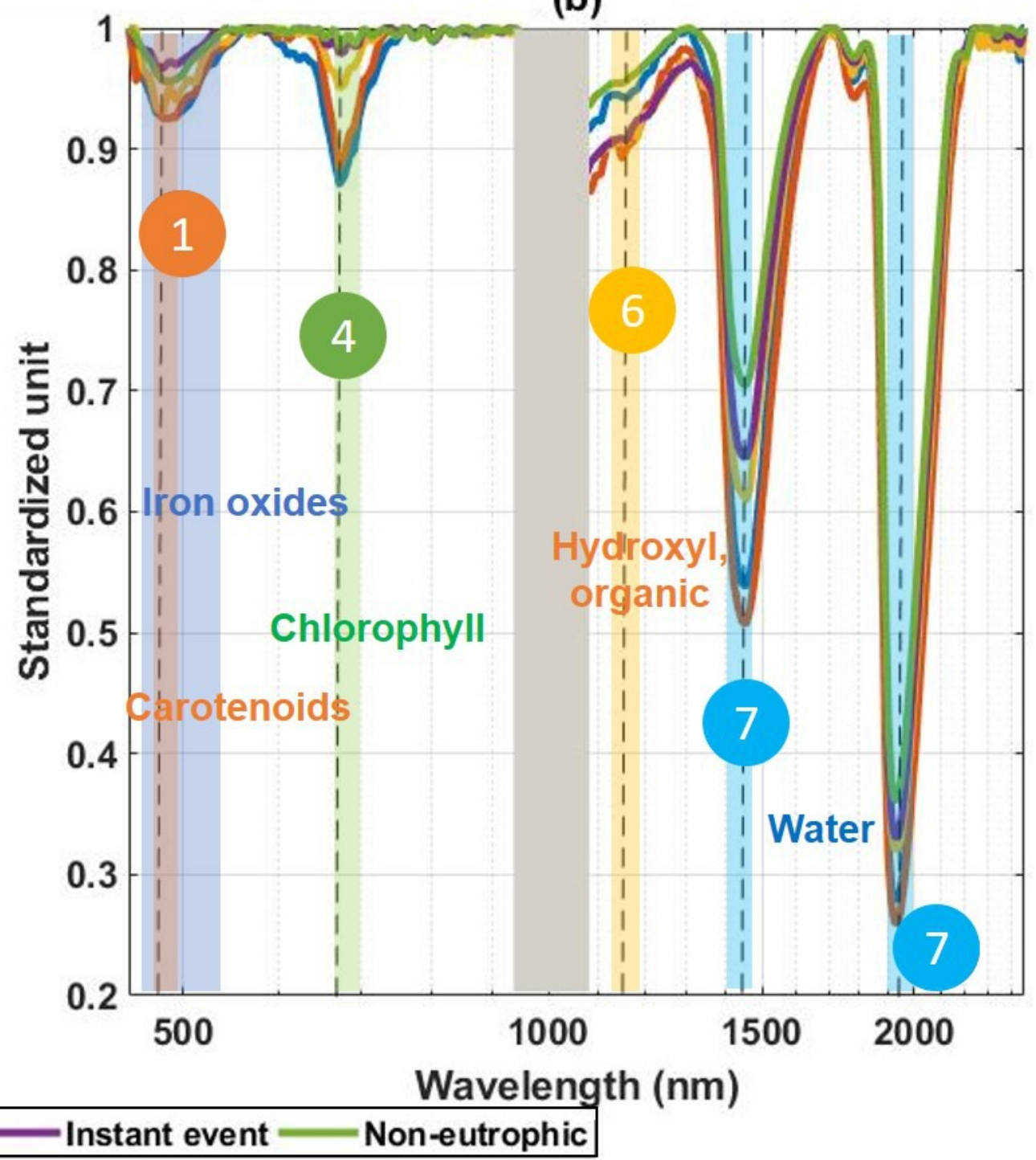




\begin{tabular}{|l|c|c|c|}
\hline Name & $\begin{array}{c}\text { Spectral } \\
\text { range }(\mathrm{nm})\end{array}$ & $\begin{array}{c}\text { Spectral } \\
\text { resolution }\end{array}$ & $\begin{array}{c}\text { Spatial } \\
\text { resolution }(\mu \mathrm{m})\end{array}$ \\
\hline Visible and Near InfraRed (VNIR) & $400-1000$ & 6 & 50 \\
\hline Short-Wave InfraRed (SWIR) & $968-2574$ & 12 & 200 \\
\hline
\end{tabular}




\begin{tabular}{|c|c|c|c|c|c|c|c|c|c|c|}
\hline & & \multicolumn{3}{|c|}{ Reference } & \multicolumn{6}{|c|}{ Prediction } \\
\hline & $n$ & $\begin{array}{l}\text { Range } \\
(\%)\end{array}$ & $\begin{array}{l}\text { Mean } \\
(\%)\end{array}$ & $\begin{array}{l}\text { Std } \\
(\%)\end{array}$ & LV & wl & $\mathbf{r}_{\mathrm{cal}}$ & $r_{\text {val }}$ & $\begin{array}{l}\text { Unc. } \\
(\%)\end{array}$ & $r_{v / s}$ \\
\hline $\begin{array}{l}\text { Clay } \\
(1-3.9 \mu \mathrm{m})\end{array}$ & \multirow{5}{*}{18} & $\begin{array}{l}14.33- \\
67.85\end{array}$ & 39.94 & 18.06 & 4 & 21 & 0.91 & 0.94 & 7.39 & 0.96 \\
\hline $\begin{array}{l}\text { Silt } \\
(3.9-62.5 \mu \mathrm{m})\end{array}$ & & $\begin{array}{l}30.49- \\
71.09\end{array}$ & 53.56 & 13.40 & 7 & 11 & 0.91 & 0.90 & 9.01 & 0.92 \\
\hline $\begin{array}{l}\text { Very Fine Sand } \\
(62.5-125 \mu \mathrm{m})\end{array}$ & & $0.44-9.33$ & 4.11 & 3.06 & 4 & 7 & 0.86 & 0.95 & 1.32 & 0.89 \\
\hline $\begin{array}{l}\text { Fine Sand } \\
(125-250 \mu \mathrm{m})\end{array}$ & & $0.05-5.36$ & 1.77 & 1.63 & 4 & 6 & 0.93 & 0.95 & 0.86 & 0.69 \\
\hline $\begin{array}{l}50 \text { PSD classes } \\
\text { (averaged values) }\end{array}$ & & $0.68-3.40$ & 1.99 & 0.90 & 4 & 44 & 0.85 & 0.83 & 0.71 & 0.93 \\
\hline
\end{tabular}




\begin{tabular}{|l|l|l|l|}
\hline Fraction & Correlation (p-value) & Bias (\%) & $\mathbf{r}_{\mathrm{V} / \mathrm{s}}$ \\
\hline Clay $(\mathbf{1 - 3 . 9} \boldsymbol{\mu \mathrm { m } )}$ & $0.95(<0.05)$ & 2.14 & 0.91 \\
\hline Silt $(\mathbf{3 . 9}-\mathbf{6 2 . 5} \boldsymbol{\mu \mathrm { m } )}$ & $0.61(<0.05)$ & 9.17 & 0.93 \\
\hline Very Fine Sand $(\mathbf{6 2 . 5 - 1 2 5} \boldsymbol{\mu \mathrm { m } )}$ & $0.94(<0.05)$ & 0.03 & 0.77 \\
\hline Fine Sand $(\mathbf{1 2 5 - 2 5 0} \boldsymbol{\mu m})$ & $0.92(<0.05)$ & -0.20 & 0.72 \\
\hline
\end{tabular}

